\title{
Screening Kelarutan Komponen SNEDDS Ekstrak Minyak Biji Mahoni (Swietenia mahagoni (Linn.))
}

\author{
Nurista Dida Ayuningtyas ${ }^{1 *}$, Agustina Putri Pitarisa $\mathbf{S}^{2}$, Silmi Mey Aryani ${ }^{3}$ \\ 1,2,3 D III Farmasi, Sekolah Tinggi Ilmu Farmasi Nusaputera, Indonesia \\ *email: nuristad@gmail.com
}

\begin{abstract}
Mahogany seed oil extract has pharmacological activities antimicrobial, antihypertensive, and anti-inflammatory. This potential can be developed into pharmaceutical dosage forms that are more practical to use. SNEDDS preparation is a dosage form that allows lipophilic active substances to be delivered to the target side of the drug. SNEDDS has oil, surfactant and cosurfactant components. In this study, the solubility of these components will be screened with mahogany seed oil extract. After finding the solubility of each component, the SNEDDS formula for mahogany seed oil extract was made. The oils used were oleic acid, VCO and IPM, cremophor surfactants RH40 and Tween 80, and co-surfactants PEG 400 and propylene glycol. The results of the solubility test were the largest components of SNEDDS, namely the components of oleic acid oil $(98.4+0.00)$, cremophor RH40 (100.0+0.00), and PEG 400 $(100.6+0.51)$. The SNEDDS formula for mahogany seed oil extract was made with a combination of oleic acid: cremophor RH40: PEG 400 1:8:1 with $200 \mathrm{~L}$ of extract. The characteristics of SNEDDS obtained are transmittance value of $98.83+0.06 \%$, pH $5.8+0.24$, and emulsification time of $34.33+6.66$ seconds with grade A where SNEDDS quickly forms nanoemulsions in 1 minute, has a good appearance. clear.
\end{abstract}

Keywords: Mahagonay, Solubility, SNEDDS,

\begin{abstract}
Abstrak
Ekstrak minyak biji mahoni memiliki aktifitas farmakologi yaitu antimikroba, antihipertensi, dan antiinflamasi. Potensi tersebut dapat dikembangkan ke dalam bentuk sediaan farmasi yang lebih praktis digunakan. Sediaan SNEDDS merupakan bentuk sediaan yang memungkinkan zat aktif yang bersifat lipofil untuk dihantarkan ke sisi target obat. SNEDDS memiliki komponen minyak, surfaktan dan ko surfaktan. Pada penelitian ini akan dilakukan screening kelarutan komponen tersebut dengan ekstrak minyak biji mahoni. Setelah ditemukan kelarutan masingmasing komponen kemudian dilakukan pembuatan formula SNEDDS ekstrak minyak biji mahoni. Minyak yang digunakan yaitu asam oleat, VCO dan IPM, surfaktan cremophor RH40 dan Tween 80, dan ko surfaktan PEG 400 dan propilenglikol. Hasil uji kelarutan paling besar komponen SNEDDS yaitu komponen minyak asam oleat $(98.4 \pm 0.00)$, cremophor RH40 $(100.0 \pm 0.00)$, dan PEG $400(100.6 \pm 0.51)$. Formula SNEDDS ekstrak minyak biji mahoni dibuat dengan kombinasi asam oleat : cremophor RH40 : PEG 400 1:8:1 dengan ekstrak sebanyak

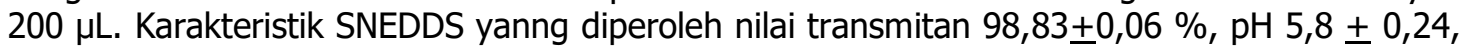
dan waktu emulsifikasi 34,33 $\pm 6,66$ detik dengan grade A dimana SNEDDS cepat membentuk nanoemulsi dalam 1 menit, memiliki penampilan yang jernih.
\end{abstract}

Kata kunci: Kelarutan, Mahoni, SNEDDS,

\section{Pendahuluan}

Nanoteknologi saat ini menjadi popular dalam bidang kefarmasian khususnya dalam pengembangan bentuk sediaan farmasi. Skala ukuran nano dapat meningkatkan kerja penghantaran obat dan meningkatkan efek terapi. Keuntungan dari nanoteknologi yaitu dapat meningkatkan kelarutan obat yang bersifat hidrofilik, meningkatkan permeabilitas transport obat di BCS kelas III dan IV, memodulasi distribusi dan 


\section{Prosiding Seminar Nasional Kesehatan 2021 LembagaPenelitian dan Pengabdian Masyarakat Universitas Muhammadiyah Pekajangan Pekalongan}

penghantaran obat, mencegah degradasi obat dan dapat menghantarkan obat secara tertarget di tempat aksi obat [1]. Nanoteknologi terbagi dalam lipid-based nanocarriers, polymeric nanocarriers, inorganic nanocarries, dan drug nanoparticels atau nanosuspensions. Lipid nanocarriers dapat berupa micelle, liposom, mikroemulsi, nanoemulsi, solid lipid nanopartikel. SNEDDS (Self Nano Emulsifiying Drug Delivery System) merupakan suatu formulasi nanopartikel berbasis minyak atau lemak. SNEDDS terdiri atas campuran isotropic antara minyak, surfaktan, dan kosurfaktan yang dapat membentuk nanoemulsi secara spontan ketika kontak dengan cairan lambung [2]. SNEDDS mempunyai karakteristik transparan, tembus cahaya dalam sistem emulsi dan merupakan dispersi minyak air yang distabilkan dengan lapisan film surfaktan atau surfaktan molekul, dan ukuran partikel yang terbentuk < $200 \mathrm{~nm}$ [3].

Swietenia mahagoni (Linn.) dikenal juga sebagai mahoni merupakan tanaman yang tumbuh di daerah tropis seperti Indonesia. Mahoni memiliki bagian tanaman biji yang secara tradisional digunakan untuk pengobatan hipertensi, diabetes, dan malaria. Pada penelitian lainnya juga dilaporkan bermanfaat pada terapi kanker, amoebiasis,dan batuk [4]. Minyak Biji Mahoni berdasarkan penilitian in vitro memberikan penghambatan terhadap enzim a-amilase dan a glukosida sebanyak 100,0 $\pm 0,3 \%$. Berdasarkan data tersebut minyak biji mahoni berpotensi sebagai antidiabetes [5].

Pengembangan sediaan farmasi dengan bahan aktif bersifat lipofil, dibutuhkan bentuk sediaan seperti SNEDDS yang dapat mengikat fase lipid dalam sediaan. Penelitian ini dilakukan untuk mendapatkan komponen penyusun SNEDDS yaitu fase minyak, surfaktan dan ko surfaktan yang dapat melarutkan bahan aktif ekstrak etanol minyak biji mahoni.

\section{Metode}

Alat : Neraca digital (AND GF-600), Waterbath, Corong pisah (Pyrex), Spektrofotometer Uv-Vis (Shimadzu Series 1700), Ultrasonik (PS-10A), Vortex (Scilogex MS7H550-S), Labu takar (Pyrex), Gelas ukur (Pyrex), Beaker glass (Pyrex), Mikropipet (Boeco).

Bahan : Biji mahoni, etanol 96\% (Bratachem), $\mathrm{HCl}$ (Bratachem), $\mathrm{NH} 4 \mathrm{OH}$ (Bratachem), $\mathrm{H}_{2} \mathrm{SO} 4$ (Bratachem), Pereaksi Mayer, Wagner, Dragendrof, $\mathrm{FeCl} 3$ (Bratachem), Akua dest (Bratachem), Asam oleat (Bratachem), Isopropil miristat, (Bratachem), VCO (Bratachem), PEG 400 (Bratachem), Propilenglikol (Bratachem), Cremophor RH40 (Bratachem), Tween 80 (Bratachem).

Metode :

a. Ekstraksi Minyak Biji Mahoni

Serbuk biji mahoni ditimbang sebanyak 500 gram, kemudian ditambahkan pelarut etanol $96 \%$ sebanyak 5 L. Campuran dimaserasi selama 5 hari sambil diaduk. Dilakukan penyaringan untuk memisahkan filtrat, filtrat diuapkan dengan waterbath suhu $70^{\circ} \mathrm{C}$. Ekstrak yang diperoleh akan memisah menjadi duabagian yaitu bagian minyak dan bagian padat berupa lemak. Bagian minyak dipisahkan dengan menggunakan corong pisah dan digunakan untuk pembuatan sediaan. 


\section{Prosiding Seminar Nasional Kesehatan 2021 LembagaPenelitian dan Pengabdian Masyarakat Universitas Muhammadiyah Pekajangan Pekalongan}

b. Skrining Fitokimia Ekstrak Minyak Biji Mahoni

Uji Flavonoid : 0,1 gram sampel ekstrak ditambahkan $5 \mathrm{~mL}$ pelarut etanol. Ditambah dengan $\mathrm{HCL}$ pekat 3 tetes dan $\mathrm{Mg}$. Apabila timbul warna kuning jingga hingga merah maka positif mengandung flavonoid [2].

Uji Alakaloid : Sebanyak 0,1 gram ekstrak dilarutkan dalam $10 \mathrm{~mL} \mathrm{CHCl}_{3}$ dan 4 tetes $\mathrm{NH}_{4} \mathrm{OH}$. Larutan disaring, filtratnya dimasukan ke dalam tabung reaksi tertutup, dan dikocok dengan 10 tetes $\mathrm{H}_{2} \mathrm{SO} 42 \mathrm{M}$. Lapisan asam dipisahkan ke dalam tabung reaksi lain, lalu diteteskan pada lempeng tetes dan ditambahkan pereaksi Mayer, Wagner, dan Dragendorf. Timbulnya endapan berturut-turut putih, coklat, dan merah jingga menunjukkan keberadaan alkaloid [6].

Uji Tanin : Sebanyak 0,1 gram ekstrak ditambahkan $10 \mathrm{~mL}$ air panas, dididihkan selama 5 menit, dan disaring. Sebagian filtrat yang diperoleh ditambahkan larutan $\mathrm{FeCl}_{3} 1 \%$. Hasil positif ditunjukkan oleh warna hijau kehitaman [6].

c. Uji Kelarutan Ekstrak Minyak Biji Mahoni

$1,0 \mathrm{~mL}$ sampel ekstrak minyak biji mahoni diuji kelarutan dengan penambahan 1,0 mL masing-masing Cremophor RH40, Tween 80 (Surfaktan), PEG 400, Propilenglikol (Ko-Surfaktan), dan Asam oleat, VCO, IPM (Fase Minyak). 100,0 $\mu \mathrm{L}$ campuran ekstrak, surfaktan, ko-surfaktan, dan minyak kemudian diukur transmitan dengan menggunakan Spektrofotometer Uv-Vis pada panjang gelombang $650 \mathrm{~nm}$ [2].

d. Pembuatan SNEDDS Ekstrak Minyak Biji Mahoni

Proses pembuatan SNEDS dilakukan dengan cara $200 \mu \mathrm{L}$ ekstrak minyak biji mahoni ditambahkan komponen 1 bagian komponen minyak, 8 magian komponen surfaktan dan 1 bagian komponen ko surfaktan. Campuran kemudian dimasukkan kedalam vial gelas dan dilakukan pengadukan menggunakan vortex selama 10 menit, kemudian dilanjutkan dengan sonikasi selama 10 menit dalamsuhu $45^{\circ} \mathrm{C}$ [7].

e. Evaluasi SNEDDS Ekstrak Minyak Biji MahoniUji Transmitan

Sebanyak $100 \mu \mathrm{L}$ formula SNEDDS diencerkan dengan $100 \mathrm{~mL}$ akua dest. Pengukuran persen transmitan dilakukan menggunakan Spektrofotometer UV-Vis pada panjang gelombang $650 \mathrm{~nm}$. Pada pengujian digunakan aquadest sebagai blanko [8].

Uji $\mathrm{pH}$

SNEDDS $100 \mu \mathrm{L}$ dilarutkan dalam $5 \mathrm{~mL}$ akua dest, nanoemulsi yang terbentuk dilakukan pengukuran $\mathrm{pH}$ dengan $\mathrm{pH}$ meter [9].

Uji Waktu Emulsifikasi

1,0 mL SNEDDS diteteskan dalam $500 \mathrm{~mL}$ akua dest dan diaduk dengan magnetic stirrer dengan kecepatan $120 \mathrm{rpm}$. Pengamatan dilakukan denganmelihat waktu dimana SNEDDS menjadi homogen [9].

\section{Hasil dan Pembahasan Hasil}

Biji Mahoni diesktraksi dengan metode maserasi, hasil maserasi berupa filtrat kemudian dipisahkan dan diuapkan untuk menghilangkan pelarut sehingga 


\section{Prosiding Seminar Nasional Kesehatan LembagaPenelitian dan Pengabdian Masyarakat Universitas Muhammadiyah Pekajangan Pekalongan}

menghasilkan ekstrak kental. Hasil Ekstrak Minyak Biji Mahoni berbentuk cair dengan dua bagian yang terpisah yaitu minyak dan lemak, berwarna coklat dan berbau pahit menyengat.

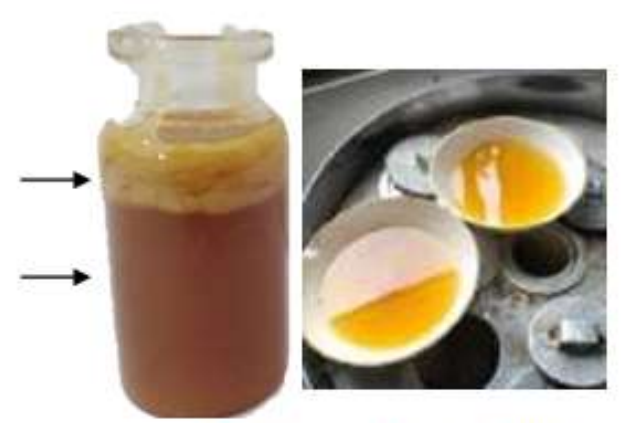

\section{Gambar 1. Ekstrak Minyak Biji Mahoni}

Ekstrak yang sudah diperoleh dipisahkan bagian minyak dan lemak, kemudian bagian minyak dilakukan skrining fitokimia untuk melihat secara kualitatif kandungan fitokimia dalam ekstrak.

Tabel 1. Skrining Fitokimia Ekstrak Minyak Biji Mahoni

\begin{tabular}{|c|c|c|c|}
\hline Identifikasi & Pengamatan & Gambar Hasil & Kesimpulan \\
\hline Flaxonoid & Warna kuning. & & $(+)$ \\
\hline Alkaloid & $\begin{array}{l}\text { Terbentuk endapan } \\
\text { putih, merah dan coklat }\end{array}$ & & $(+)$ \\
\hline Janin & $\begin{array}{l}\text { Jerbentuk } \\
\text { putih. }\end{array}$ & & $(+)$ \\
\hline
\end{tabular}

Berdasarkan hasil skrining fitokimia ekstrak minyak biji mahoni memilliki kandungan aktif flavonoid, alkaloid dan tanin. Hasil uji sesuai dengan penelitian yang dilakukan Yashota, dkk [10]. Ekstrak minyak biji mahoni diformulasikan dalam bentuk SNEDDS (Self Nano Emulsifiying Drug Delivery System). SNEDDS memungkinkan untuk menghantarkan obat dalam bentuk lipofilik ke sisi target terapi. Tahap awal yang dilakukan yaitu uji kelarutan minyak dalam masing-masing komponen SNEDDS yaitu surfaktan, ko surfaktan dan minyak. 
Prosiding Seminar Nasional Kesehatan LembagaPenelitian dan Pengabdian Masyarakat

2021 Universitas Muhammadiyah Pekajangan Pekalongan

Tabel 1. Hasil Uji Kelarutan Ekstrak Minyak Biji Mahoni

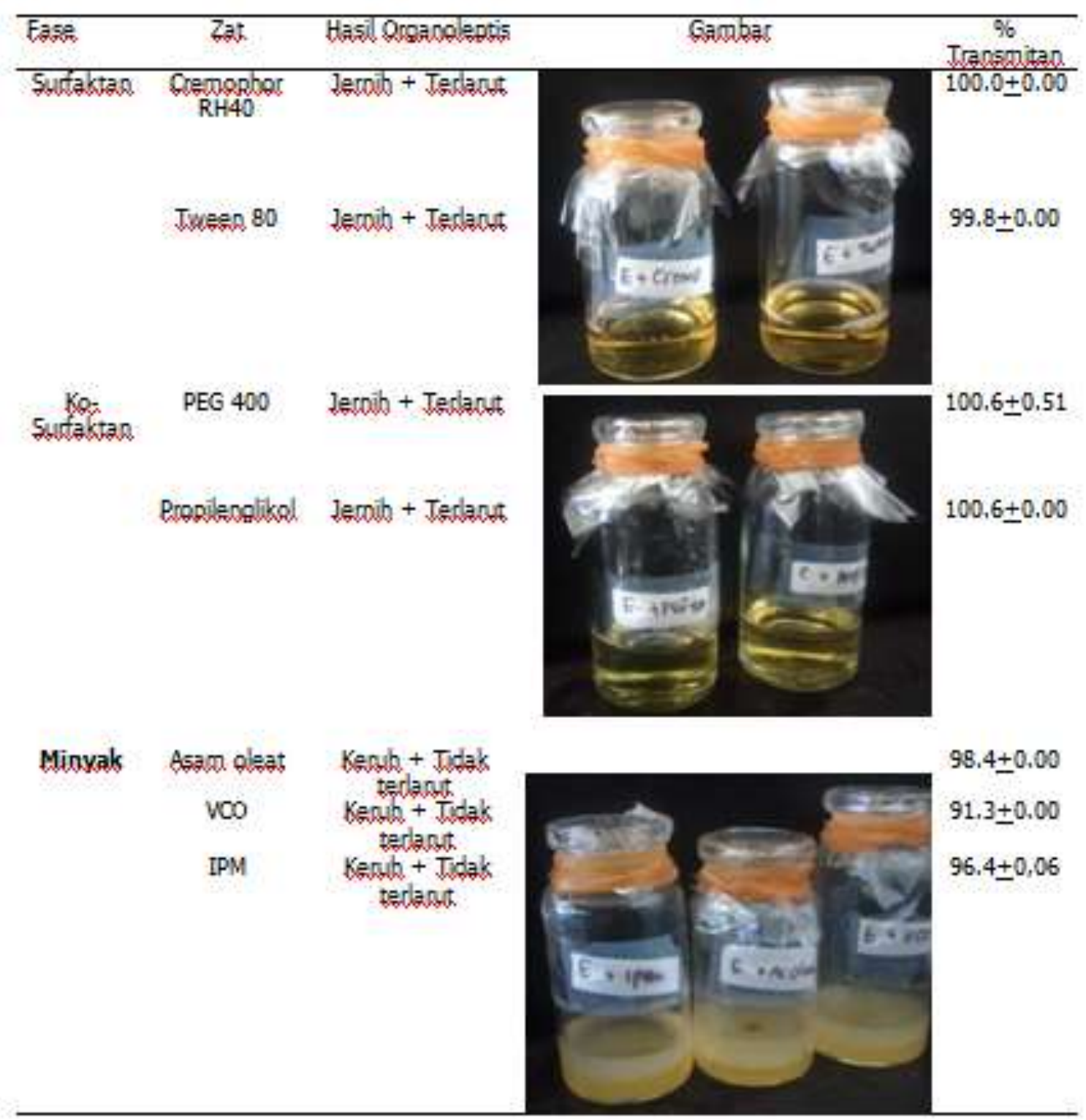

Ekstrak minyak biji mahoni sebanyak $200 \mu \mathrm{L}$ ditambahkan campuran 8,0 mL Cremophor RH40, 1,0 mL PEG 400, dan 1,0 mL asam oleat. SNEDDS yang terbentuk berwarna kuning transparan, cair dan tidak berbau.

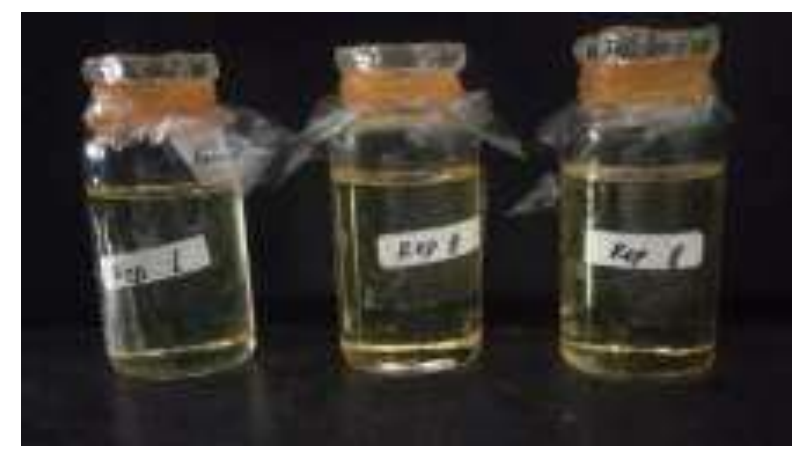




\section{Prosiding Seminar Nasional Kesehatan 2021 LembagaPenelitian dan Pengabdian Masyarakat Universitas Muhammadiyah Pekajangan Pekalongan}

Gambar 2. Formula SNEDDS Ekstrak Minyak Biji Mahoni Formula yang sudah terbentuk kemudian dilakukan evaluasi \% transmitan, pH dan waktu emulsifikasi.

Tabel 3. Uji Formula SNEDDS Ekstrak Minyak Biji Mahoni

\begin{tabular}{cccc}
\hline Replikasi & \% Transmitan & pH & Waktu emulsifikasi (detik) \\
\hline 1 & 99 & 5,92 & 31 \\
2 & 98,9 & 5,53 & 30 \\
3 & 98,9 & 5,96 & 42 \\
\hline Rerata & 98,83 & 5,80 & 34,33 \\
\hline SD & 0,06 & 0,24 & 6,66 \\
\hline
\end{tabular}

\section{Pembahasan}

Biji Mahoni (Swietenia mahagoni L) merupakan tanaman dari famili Meliaceae. Biji mahoni yang telah dilakukan sortasi kering dilakukan penghalusan untuk memperkecil ukuran partikel dari simplisa. Serbuk yang diperoleh kemudian dilakukan ekstrasi dengan pelarut etanol 96\% yang bersifat semipolar dengan indeks polaritas sebesar 5,2 [11]. Pelarut yang semipolar akan menarik zat aktif yang terdapat dalam simplisia seperti alkaloid, tanin, dan flavonoid [12]. Proses ekstrasi dilakukan dengan maserasi kelebihan metode ini yaitu dapat menarik zat padaa suhu ruang. Pelarut akan masuk dan memecah sel simplisia, sehingga zat aktif tertarik keluar sel. Setelah 3 hari campuran dipisahkan filtrat dan rendemen [13].

Kandungan aktif dari minyak biji mahoni telah diketahui memiliki aktifitas farmakologi sebagai antimikroba, antiinflamasi, hepatoprotektif, antidiabetik dan gastroprotektif [14]. Berdasarkan hal itu maka minyak biji mahoni berpotensi untuk dikembangkan dalam bentuk sediaan farmasi yang lebih praktis digunakan dan stabil untuk penyimpanan yang lama. SNEDDS yang merupakan campuran isotropic dari minyak, surfaktan dan ko surfaktan merupakan bentuk sediaan yang dapat menghantarkan obat lipofilik ke tempat aksi. SNEDDS akan terlarut membentuk nanoemulsi dengan penambahan media air atau jika dalam tubuh ketika bertemu dengan cairan gastrointestinal [14].

Pada pembuatan dilakukan uji kelarutan ekstrak minyak biji mahoni dalam surfaktandan ko surfaktan didapatkan hasil campuran Cremophor RH40 dan PEG 400 menunjukkan nilai transmitan yang lebih besar. Pada SNEDDS surfaktan dan kosurfaktan yang mampu bercampur baik dengan fase minyak akan meningkatkan efektivitas pembentukan sistem emulsi. Surfaktan dan ko-surfaktan dalam sistem nanoemulsi bekerja sama membentuk sistem antarmuka yang baik dan flexibel, serta menurunkan nilai tegangan permukaan sampai mendekati nol sehingga mendukung terbentuknya globul berukuran nano yang stabil [8]. Ekstrak minyak biji mahoni memiliki komposisi asam lemak seperti asam palmitat, asam palmitolik, asam stearat, asam oleat, dan asam linoleat [15]. Karena adanya kandungan asam oleat pada ekstrak minyak biji mahoni maka eksstrak lebih mudah terlarut dalam fase minyak asam oleat yang merupakan Monounsaturated Fatty Acid (MUFA) [8].

Uji kejernihan SNEDDS diamati dengan pengukuran \% transmitan dengan menggunakan Spektrofotometer Uv-Vis. Hasil uji diperoleh nilai transmitan 98,83+0,06 


\section{Prosiding Seminar Nasional Kesehatan $\mathbf{2 0 2 1}$ LembagaPenelitian dan Pengabdian Masyarakat Universitas Muhammadiyah Pekajangan Pekalongan}

\%. Nilai transmitan yang mendekati $100 \%$ menunjukkan bahwa SNEDDS menghasilkan dispersi jernih dan transparan dengan ukuran tetesan diperkirakan mencapai nanometer. Ukuran fase terdispersi sangat mempengaruhi penampilan emulsi jernih atau keruh, hal ini karena ukuran droplet-droplet minyak yang terdispersi dalam air. Bila sistem emulsi yang memiliki ukuran droplet sangat kecil dilewati cahaya, maka berkas cahaya akan diteruskan sehingga warna larutan terlihat transparan dan transmitan yang dihasilkan semakin besar [16].

$\mathrm{pH}$ merupakan parameter yang juga diukur dalam sediaan SNEDDS. Pengukuran dilakukan dengan pelarut akua dest dan diukur menggunakan $\mathrm{pH}$ meter. Nilai standar pH SNEDDS yaitu 6,5-9,0 [17]. Hasil uji SNEDDS ekstrak minyak biji mahoni dibawah pH standar SNEDDS yaitu 5,8 $\pm 0,24$, hal ini kemungkinan disebabkan karena cremophor RH40 memiliki pH 5-7 [18].

Uji waktu emulsifikasi dilakukan untuk melihat lama waktu SNEDDS membentuk emulsi setelah bereaksi dengan cairan lambung. Hasil menunjukkan bahwa waktu emulsifikasi formula sebesar 34,33 $\pm 6,66$ detik, dimana kurang dari 1 menit yang merupakan syarat dari SNEDDS [16]. Berdasarkan hasil uji tersebut, SNEDDS yang terbentuk termasuk dalam grade A dimana SNEDDS cepat membentuk nanoemulsi dalam 1 menit, memiliki penampilan yang jernih [19].

\section{Kesimpulan}

Ekstrak minyak biji mahoni dapat dibuat dalam sediaan SNEDDS (Self Nano Emulsifiying Drug Delivery System) dengan kombinasi komponen surfaktan cremophor RH40, ko surfaktan PEG 400, dan minyak asam oleat. Hasil uji karakteristik SNEDDS diperoleh nilai transmitan 98,83+0,06 \%, pH 5,8 \pm 0,24, dan waktu emulsifikasi 34,33 $\pm 6,66$ detik. SNEDDS ekstrak minyak biji mahoni yang diperoleh termasuk dalam Grade A dimana SNEDDS cepat membentuk nanoemulsi dalam 1 menit, memiliki penampilan yang jernih.

\section{Ucapan Terima Kasih}

Penulis mengucapkan terima kasih kepada Sekolah Tinggi Ilmu Farmasi Nusaputera yang mengijinkan melakukan penelitian ini dan Kementerian Riset dan Teknologi atas pendanaan Hibah Penelitian Dosen Pemula tahun 2021 dengan nomor kontrak 067/E4.1/AK.04.PT/2021.

\section{Referensi}

[1] A. A. Date, N. Desai, R. Dixit, and M. Nagarsenker, "Self-nanoemulsifying drug delivery systems: Formulation insights, applications and advances," Nanomedicine, vol. 5, no. 10, pp. 1595-1616, 2010.

[2] S. Indratmoko, S. D. Cahyani, and A. Tenri, "Optimasi Formula SNEDDS Ekstrak Etanol Daun Sirsak (Annona muricata) sebagai Antibakteri (Stapylococcus aureus) Dengan Metode Simplex Lattice Design," J. Ilm. Kefarmasian, pp. 6570, 2020.

[3] S. R. Sokkula and S. Gande, "A Comprehensive Review on Self-Nano 


\section{Prosiding Seminar Nasional Kesehatan 2021 LembagaPenelitian dan Pengabdian Masyarakat Universitas Muhammadiyah Pekajangan Pekalongan}

Emulsifying Drug Delivery Systems: Advancements \& Applications," Int. J. Pharm. Sci. Drug Res., vol. 12, no. 5, pp. 576-583, 2020.

[4] G. Sahgal, S. Ramanathan, S. Sasidharan, M. N. Mordi, S. Ismail, and S. M. Mansor, "Phytochemical and antimicrobial activity of Swietenia mahagoni crude methanolic seed extract," Trop. Biomed., vol. 26, no. 3, pp. $274-279,2009$.

[5] N. F. A. Bakar, N. A. Bakeri, L. M. Salleh, H. A. Perseni, M. L. Hilmi, and D. N. A. Zaidel, "Extraction of swietenia macrophylla seed oil using supercritical carbon dioxide technique and its antioxidant, antidiabetic and toxicity properties," Chem. Eng. Trans., vol. 78, pp. 523-528, 2020.

[6] Z. Hajli, "Isolasi Senyawa Golongan Flavonoid Biji Mahoni (Swieteniamahagoni Jacq) yang Berpotensi Sebagai Antioksidan," Dep. Kim. Fak. MIPA Inst. Pertan. Bogor, 2011.

[7] W. Wulandari, D. E. Ermawati, and A. Yugatama, "Optimization SNEDDS (SelfNano Emulsifying Drug Delivery System) of ZnO that dispersed into Hydrogel Matrix as UV-Protective," IOP Conf. Ser. Mater. Sci. Eng., vol. 578, no. 1, 2019.

[8] S. E. Priani, S. Y. Somantri, and R. Aryani, "Formulasi dan Karakterisasi SNEDDS (Self Nanoemulsifying Drug Delivery System) Mengandung MinyakJintan Hitam dan Minyak Zaitun," J. Sains Farm. Klin., vol. 7, no. 1, p. 31,2020.

[9] L. Pratiwi, A. Fudholi, R. Martien, and S. Pramono, "Self-nanoemulsifying drug delivery system (Snedds) for topical delivery of mangosteen peels (Garcinia Mangostana I.,): Formulation design and in vitro studies," J. Young Pharm., vol. 9, no. 3, pp. 341-346, 2017.

[10] P. Yasotha, K. Sangeetha, and R. Rajendran, "Phytochemical and Antimicrobial Potential of Seed and Bark Extracts of Swietenia Mahagoni (L.) Jacq.," Int. J. Pharm. Sci. Res., vol. 10, no. 2, pp. 712-720, 2019.

[11] R. Abarca-Vargas, C. F. Peña Malacara, and V. L. Petricevich, "Characterization of chemical compounds with antioxidant and cytotoxic activities in bougainvillea $\mathrm{x}$ buttiana holttum and standl, (Var. rose)extracts," Antioxidants, vol. 5, no. 4, 2016.

[12] Amita Pandey and S. Tripathi, "Extraction of Pharmaceutical Drugs. 2014,"

J. Pharmacogn. Phytochem., vol. 2, no. 5, pp. 115-119, 2014.

[13] A. Nn, "A Review on the Extraction Methods Use in Medicinal Plants, Principle, Strength and Limitation," Med. Aromat. Plants, vol. 04, no. 03, pp. 3-8, 2015.

[14] Y. P. uttaswam. Naveen, G. Divya Rupini, F. Ahmed, and A. Urooj, "Pharmacological effects and active phytoconstituents of Swietenia mahagoni: a review," J. Integr. Med., vol. 12, no. 2, pp. 86-93, 2014.

[15] B. Suliman, "Fatty acid composition and antibacterial activity of Swietenia Macrophylla king seed oil," African J. Plant Sci., vol. 7, no. 7, pp. 300-303, 2013. 


\section{Prosiding Seminar Nasional Kesehatan LembagaPenelitian dan Pengabdian Masyarakat Universitas Muhammadiyah Pekajangan Pekalongan

[16] N. Huda and I. Wahyuningsih, "Karakterisasi Self-Nanoemulsifying Drug Delivery System (SNEDDS) Minyak Buah Merah (Pandanus conoideusLam.)," J. Farm. Dan Ilmu Kefarmasian Indones., vol. 3, no. 2, p. 49, 2018.

[17] Y. Zhao et al., "Self-nanoemulsifying drug delivery system (SNEDDS) for oral delivery of Zedoary essential oil: Formulation and bioavailability studies," Int. J. Pharm., vol. 383, no. 1-2, pp. 170-177, 2010.

[18] M. E. Q. Raymon C Rowe, Paul J Sheskey, Handbook Of Pharmaceutical Excipient, VI. Pharmaceutical Press, 2009.

[19] S. E. Priani, N. Nurrayyan, and F. Darusman, "Formulation self nano emulsifying drug delivery system glimepiride using oleic acid as oil phase,"Pharmaciana, vol. 7, no. 2, p. 267, 2017. 